\title{
Justicia distributiva Distributive Justice
}

\author{
Fernando Aguiar González \\ IFS-CSIC \\ ORCID ID 0000-0001-7787-2075 \\ faguiar@cchs.csic.es
}

\section{Cita recomendada:}

Aguiar González, F. (2019). Justicia distributuva. Eunomía. Revista en Cultura de la Legalidad, 17, $207-219$. doi: https://doi.org/10.20318/eunomia.2019.5025

Recibido / received: 06/06/2018 Aceptado / accepted: 20/02/2019

\begin{abstract}
Resumen
En este artículo se realiza un breve recorrido por las teorías de la justicia distributiva más influyentes, partiendo de John Rawls y terminando con los principios propuestos por Martha Nussbaum para el desarrollo de una justicia global. En ese recorrido veremos cómo responden esas teorías a tres preguntas: qué se distribuye, cómo se distribuye y entre quiénes se distribuye. Esto nos permitirá comparar sus fundamentos y sus principios de distribución justa, así como comprender mejor sus límites.
\end{abstract}

\section{Palabras clave}

Bienes primarios, capacidades, comunidad, igualdad, justicia global, principio de diferencia, renta básica, suerte, utilitarismo.

\begin{abstract}
This article offers a brief overview of the most influential theories of distributive justice, starting with John Rawls and ending up with Martha Nussbaum's principles for a global justice. Along this way we will see how they answer these three questions: what to distribute, how it is distributed and among whom it is distributed. This will allow us to compare its foundations and principles of fair distribution, as well as to better understand its limits.
\end{abstract}

\section{Keywords}

Basic income, capabilities, community, difference principle, equality, global justice, luck, primary goods, utilitarianism.

Sumario. 1. Introducción. 2. ¿Qué se distribuye y cómo? Rawls, los dos principios de justicia y los bienes primarios. 3. Recursos, utilidades y capacidades: Dworkin, van Parijs, Harsanyi y Sen. 4. Justicia, mercado y derechos: Robert Nozick. 5. ¿Entre quiénes se distribuye? Comunitarismo, cosmopolitismo y fronteras de la justicia. 


\section{Introducción}

El concepto de igualdad es puramente relacional. Podemos afirmar que Antonia es libre pero no podemos decir, sin añadir algo más, que Antonia es igual. ¿lgual con respecto a quién? ¿Igual en qué? La estructura lógica del concepto de igualdad debe responder a la siguiente fórmula: $X$ es igual a $Y$ en $Z$ (Bobbio, 1993). Por lo tanto, hay que preguntarse antes de nada entre quiénes se da esa igualdad: los seres humanos, las mujeres, los hombres, los ciudadanos, los niños o los caballeros de la mesa redonda. Ahora bien, para que el concepto adquiera todo su sentido hay que preguntarse además en qué son iguales las personas entre las que se establece esa relación: ante la ley, en derechos y libertades, en ingresos, en oportunidades, en poder, etc. Cuando la igualdad se relaciona con recursos, beneficios y cargas sociales nos hallamos ante un problema de justicia distributiva. Pues bien, desde un punto de vista normativo, las teorías de la justicia distributiva consisten en el estudio de los principios que establecen cómo deben distribuirse (de forma igualitaria o no), y entre quiénes, los beneficios y las cargas sociales (Lamont y Favor, 2017). Estas teorías se enfrentan, por lo tanto, a tres preguntas:

a. Qué se distribuye: dinero, derechos, poder, recursos.

$b$. Cómo se distribuye: criterios normativos de justicia igualitarios o no igualitarios.

c. Entre quiénes se distribuye: la humanidad, los hombres, las mujeres, los niños, los ciudadanos, los desfavorecidos, los aristócratas.

A diferencia de la teoría normativa de la justicia, la teoría positiva nos dirá cómo se distribuyen de hecho los recursos en una región, en un país dado o en todo el mundo y entre quiénes se distribuye. Así, por ejemplo, en el año 2015 el uno por ciento de las familias más ricas poseía la mitad de la riqueza privada neta mundial, sin contar lo que pudieran tener en paraísos fiscales (Milanovic, 2018). ¿Eso es justo? A mucha gente no se lo parece, pero a otra mucha sí: sin una teoría normativa de la justicia los datos, pese a su enorme importancia, no sirven para considerar justa o no una distribución dada. Teorías de la justicia, sin embargo, hay muchas y responden de manera diversa a las tres preguntas anteriores, como vamos a ver.

2. ¿Qué se distribuye y cómo? Rawls, los dos principios de justicia y los bienes primarios

La teoría de la justicia de John Rawls ocupa un lugar tan destacado que resultaría un tanto arbitrario no empezar por ella en un texto como éste ${ }^{1}$ : su respuesta a las tres preguntas anteriores nos dará la pauta para ver cómo responden otras teorías, pues muchas de ellas lo hacen partiendo de la obra de Rawls. De manera sucinta se puede afirmar que en La teoría de la justicia Rawls trata de deducir qué criteritos de justicia distributiva adoptaría un individuo racional en un contexto de incertidumbre. Así pues, en relación con la pregunta sobre cómo se distribuye, la teoría de la justicia de Rawls es puramente procedimental. Un criterio de justicia puramente procedimental se puede ejemplificar mediante una apuesta justa (el siguiente ejemplo es del propio

\footnotetext{
${ }^{1}$ La teoría de Rawls es compleja y ha conocido a la largo de la vida del autor numerosas modificaciones desde 1971, cuando publica $A$ Theory of Justice, hasta Justice as Fairness. A Restatement, obra de 2001, pasando por $A$ Theory of Justice. Revised Edition, publicada en 1999. No podemos señalar aquí todos y cada uno de esos cambios, así que nos atendremos a un Rawls "esencial" perfectamente reconocible que se puede hallar con matices menores en todas sus obras. En el prefacio de la edición revisada Rawls resume las diferencias entre su obra de 1971 y la de 1999.
} 
Rawls): si un grupo de personas acuerda tirar un dado o hacer girar una ruleta como medio para distribuir algo, lo más probable es que el resultado beneficie a unos y perjudique a otros, pero nadie podrá decir que es injusto, aunque sea muy mejorable. ¿Qué procedimiento será entonces el más adecuado para establecer los criterios de justicia?

En primer lugar, habrá que evitar que la elección de los principios sea parcial, pues de esa forma el procedimiento quedaría deslegitimado. Para ello Rawls parte del supuesto de que esos principios se elegirán en una posición original en la que las partes son libres e iguales y, además, desconocen todo sobre sí: el tipo de sociedad en que vivirán, el lugar que ocuparán en ella, su clase social, su sexo, su inteligencia, su raza o cualesquiera otros rasgos personales o sociales que les permitan identificarse con algún interés ajeno a la justicia. Partiendo de esa posición, la teoría de la justicia como equidad o imparcialidad (justice as fairness) de John Rawls adopta un procedimiento contractualista de estirpe lockeana, rousseauniana y kantiana: individuos racionales, libres e iguales sobre los que ha caído un grueso velo de ignorancia deben establecer, mediante un contrato social hipotético, la estructura básica de la sociedad en que vivirán:

Para nosotros, el objeto primario de la justicia es la estructura básica de la sociedad o, más exactamente, el modo en que las instituciones sociales más importantes distribuyen los derechos y deberes fundamentales y determinan la división de las ventajas provenientes de la cooperación social. Por instituciones más importantes entiendo la constitución política y las principales disposiciones económicas y sociales (Rawls, 1978, p. 23).

Las partes contratantes que se hallan en la posición original deben elegir, pues, una serie de principios que regulen con justicia «el modo en que las instituciones...distribuyen» cargas y beneficios, derechos y deberes (ibíd.). Esos principios serán generales, pues no deben hacer mención de personas concretas; universales, en la medida en que pueden ser aceptados por cualquier individuo racional, y públicos, ya que servirán para dirimir los conflictos de intereses. Ahora bien, ¿de qué principios se trata?

Puesto que tras el velo de ignorancia nadie sabe cuál será su suerte en la sociedad, todo el mundo tratará de elegir, según Rawls, una concepción general de la justicia que beneficie lo más posible a los menos favorecidos. En otras palabras, con la deducción de los principios en una posición original equitativa en la que se establece un contrato social hipotético, Rawls trata de limitar los efectos del azar en la vida social, es decir, la mala suerte de estar entre los desfavorecidos. Por ello supone que la concepción general de la justicia que elegirían individuos racionales sobre los que cae un velo de ignorancia sería la siguiente:

Todos los bienes sociales primarios -libertad, igualdad de oportunidades, renta, riqueza y las bases del respeto mutuo- han de ser distribuidos por igual, a menos que una distribución desigual de uno o de todos estos bienes fuese ventajosa para los menos favorecidos (Rawls, 1978, p. 341).

En esta breve cita se da respuesta a dos de las tres preguntas que debe resolver una teoría de la justicia: qué se distribuye (bienes sociales primarios) ${ }^{2}$ y entre

\footnotetext{
2 La lista de bienes primarios que propone es Rawls es la siguiente: «(a) En primer lugar, las libertades básicas ofrecidas en una lista, por ejemplo: libertad de pensamiento y libertad de conciencia, libertad de asociación, la libertad definida por la libertad e integridad de la persona, así como por el estado de derecho; finalmente, las libertades políticas; (b) en segundo lugar, la libertad de movimiento y de elección de ocupación, en el marco de oportunidades diversas; (c) en tercer lugar, poder y prerrogativas para ocupar cargos y posiciones de responsabilidad, particularmente aquellos en las principales instituciones
} 
quiénes (los más desfavorecidos). En la de Rawls lo que se distribuye, los bienes sociales primarios, son lo que «las personas necesitan en su estatus como ciudadanos libres e iguales y como miembros normales de una sociedad que cooperan plenamente a lo largo de la vida» (Rawls 1999, p. xiii). Se trata de un concepto de bien social, pues, que entraña una concepción moral del individuo, la cual se plasma en dos «poderes morales»: el de la racionalidad (la capacidad para perseguir una concepción personal del bien) y el de razonabilidad (el sentido de la justicia). De esta forma, cabe entender que los bienes primarios son bienes que personas razonables y racionales quieren de forma universal, más allá de sus preferencias personales (Rawls 1982, p. 314; 1993, p. 302) ${ }^{3}$.

Los bienes primarios rawlsianos, además del lugar central que ocupan en la teoría, cumplen otras dos funciones relacionadas entre sí. Por un lado, suponen una crítica radical a cualquier teoría que mida el bienestar en términos de utilidades, ya se entiendan como felicidad, satisfacción de deseos, satisfacción de preferencias o de cualquier otra forma subjetiva (Rawls, 1999, pp. 19 y ss). Por otro lado, el concepto de bien primario permite a Rawls ofrecer una métrica objetiva de lo que hay que distribuir $^{4}$.

Pues bien, una vez establecida la concepción general de la justicia, los individuos situados en la posición original descartan una serie de principios que se les presentan y eligen dos, uno para la libertad (principio de igual libertad) y otro, dividido en dos partes, para los demás bienes primarios (principio de diferencia y principio de igualdad de oportunidades):

1. Cada persona ha de tener derecho por igual al más amplio sistema total de libertades básicas, compatible con un sistema similar de libertad para todos.

2. Las desigualdades económicas y sociales han de ser estructuradas de manera que sean para:

a. mayor beneficio de los menos aventajados, de acuerdo con un principio de ahorro justo, y

b. que cargos y posiciones estén abiertos a todos en condiciones de justa igualdad de oportunidades" (Rawls, 1978, p. 341; 1999, p. 266).

Para evitar conflictos entre ambos principios o entre las dos partes del segundo, Rawls establece una regla de prioridad (lexicográfica) según la cual el primer principio tiene prioridad sobre el segundo y, dentro del segundo, la segunda parte tiene prioridad sobre la primera. En ningún caso se puede violar, por lo tanto, el sistema de libertades en nombre de la igualdad, el bienestar, la eficiencia o cualquier otro valor social. Y del mismo modo, la igualdad de oportunidades no se puede violar

políticas y económicas; (d) en cuarto lugar, renta y riqueza; y (e)finalmente, las condiciones sociales del autorrespeto» (Rawls 1982: 362-363). Igualmente, en Liberalismo político Rawls señala que tal lista es flexible y puede incluir otros bienes, como tiempo de ocio y ciertos estados mentales como la ausencia de sufrimiento físico (Rawls 1993, pp. 181-182 (citado por Venezia, 2007, nota 5). Sin embargo, como señala Venezia (2007: nota 5), el propio autor reconoce que se trata de una lista flexible.

${ }^{3}$ En la teoría de la justicia original, la de 1971, Rawls considera que los bienes primarios son aquellos que querría cualquier persona racional. A su modo de ver, esto es ambiguo porque parece que los bienes dependen solo de hechos de la psicología humana en vez de entrañar más bien un ideal moral de persona. Rawls se decanta por esto último y por eso opta por la nueva definición, que es la que aparece ya como definitiva en la revisión de 1999. Otra cuestión debatida es si la idea de bienes primarios se deriva de la posición original o no. Con la primera definición es más fácil interpretar que sí, con la segunda es más difícil. Pero este es un debate que va más allá de este artículo (véase Venezia, 2007).

${ }^{4}$ Un concepto objetivo «proporciona una base para evaluar el nivel de bienestar de una persona que es independiente de los gustos e intereses de la persona en cuestión y, de esa forma, permite la posibilidad de que tal evaluación sea correcta aun cuando entre en conflicto con las preferencias del individuo en cuestión» (Scanlon, 1975, p. 658). 
nunca en nombre del principio de diferencia, aunque ello mejorara la suerte de los menos favorecidos.

\section{Recursos, utilidades y capacidades: Dworkin, Van Parijs, Harsanyi y Sen}

La teoría de Rawls promueve, en última instancia, una sociedad de personas libres, iguales y autónomas que puedan realizar su plan de vida, para lo cual se debe conjurar la mala suerte de nacer en un mundo injusto. En la sociedad rawlsiana esa incertidumbre no desaparecería, pero se reducirían mucho sus consecuencias. Ahora bien, siendo el fin más que loable, el andamiaje ha sido criticado en algunos de sus aspectos por autores cercanos filosóficamente a Rawls, ya sea en el fondo, en la forma o en ambos.

\section{1 ¿Qué se distribuye, recursos, un ingreso básico y capacidades?}

En una crítica temprana a la obra de Rawls, Ronald Dworkin pone el acento, precisamente, en el problema de la mala suerte. La teoría rawlsiana trata de suavizar los efectos de la mala suerte absoluta (brute luck), como la pobreza o la enfermedad, pero no presta la suficiente atención a la suerte opcional (option luck), esto es, la que se busca voluntariamente para poder realizar un plan de vida personal. Para remediar ese problema el autor de Virtud soberana parte también de una posición original hipotética: unos náufragos que han llegado a una isla desierta construyen la sociedad partiendo de cero. Los «inmigrantes», como los llama Dowrkin, establecen un mecanismo de distribución en dos etapas (Dworkin 2003: cap. 2). La primera implica un reparto igualitario de recursos monetarios (una gran cantidad de almejas, igual para todos), es decir, poder de compra. En una segunda etapa la gente participa en una subasta hipotética de todo tipo de recursos que les permitan llevar a cabo su plan racional de vida: la puja, por ejemplo, será mayor si se quiere ser arquitecta que poeta. La subasta finaliza cuando nadie envidia -en sentido económico, no psicológico- los recursos de los demás porque tiene lo que necesita para realizar su plan de vida.

Se trata, pues, de un procedimiento justo porque permite que todo el mundo sea tratado con igual consideración, no se privilegia a nadie. ¿Pero qué ocurre si mi plan de vida fracasa? ¿Qué ocurre si elijo de forma equivocada o, todavía peor, si tengo un accidente en plena madurez y no puedo llevar mi plan a cabo? Para prevenir la mala suerte opcional o la mala suerte absoluta sobrevenida la gente deberá contratar un seguro, pues de atenuar los golpes de la mala suerte es responsable en parte cada cual. Si Ángela, por ejemplo, que es pianista, contrata un seguro para las manos y Emilia, que también lo es, no lo contrata, Ángela no tendrá por qué asumir las consecuencias distributivas de la libre decisión de Emilia. Del mismo modo, si a Emilia no le ocurre accidente alguno en las manos disfrutará de más recursos que Ángela al no tener que pagar el seguro:

La igualdad de trato exige de hecho que una comunidad compense de alguna forma la mala suerte. Pero es preciso que entendamos esa compensación de manera que sea compatible con el adecuado respeto hacia la responsabilidad individual. Esto tiene como objetivo... que la gente afronte equitativamente tanto las decisiones económicas como las contingencias que cercan esas decisiones (Dworkin, 2011, p. 359).

Dworkin considera que ese objetivo sólo se puede lograr mediante mercados regulados de inversión, salarios y consumo en los que la genta asuma los costes que sus decisiones tienen para los demás: tales mercados son « un paso crucial hacia la igualdad » (ibíd.). A su vez, la idea del seguro nos obliga a pensar lo que supone para 
nuestras vidas la mala suerte sobrevenida y la responsabilidad de protegernos por igual frente a ella, no cargando ex post los costes a los otros. Ahora bien, a diferencia del mercado de inversiones, salarios y consumo, el seguro solo puede ser hipotético, una herramienta teórica para situar en el centro de la justicia distributiva la cuestión de la responsabilidad individual, pues ningún mercado real aseguraría a todo el mundo de forma igualitaria.

La teoría de Dworkin ha tenido gran influencia, ya que inaugura una línea de reflexión sobre justicia distributiva -el igualitarismo de la suerte (Iuck egalitarianism) - que, frente a Rawls, pone el acento en la responsabilidad individual, hace del mercado una pieza normativa clave para que las personas asuman esa responsabilidad y no se centra en la distribución de bienes primarios, sino de recursos de carácter general para llevar a cabo el plan de vida deseado.

Philipe van Parijs aboga, en cambio, por una liberación absoluta de la mala suerte social y del mercado. Aunque inicialmente su propuesta surge como una teoría marxista de la justicia, la idea de un ingreso básico garantizado que recibiría todo ciudadano por el mero hecho de serlo, se presenta en su etapa madura como una teoría de estirpe rawlsiana: «la concesión de un ingreso básico sustancial está más relacionada con el acceso a la propiedad 'activa' asociada con el ideal de Rawls de una "democracia de propietarios" que con la redistribución correctiva ex post...del estado de bienestar» (van Parijs, 1995, p. 42). Ahora bien, la distribución rawlsiana de bienes primarios no promueve una libertad y una autonomía verdaderas porque la gente, de todas formas, tiene que trabajar para vivir dignamente. Por el contrario, la libertad real para todos que se lograría mediante un ingreso ciudadano garantizado implica la absoluta desmercantilización de las personas, hasta el punto de que incluso trabajar se convierte en una opción libre más de un plan de vida personal. De esta forma, tanto los golpes de la mala suerte absoluta (pobreza, paro, discapacidad, etc.), como los de la mala suerte opcional (la elección de un plan de vida que fracasa) quedan atenuados por el ingreso básico, que es el garante de la libertad real de elección.

Sin entrar en más detalles, hay que señalar que la propuesta de van Parijs, como se ve, reduce la de Dworkin a su primera etapa, a saber, la distribución equitativa de un ingreso ciudadano igualitario (eso eran las almejas en última instancia). Sin embargo, cabría achacar a ambos, y también a Rawls, que ya se distribuyan bienes primarios, recursos de todo tipo (monetarios o no) o un ingreso básico, la pregunta que se impone es la siguiente: ¿qué puede hacer o ser la gente con esos bienes? Pensemos en el caso de una familia en la que el padre reparte los recursos de manera injusta; o en la niña tanzana que, para aprender a leer, recibe libros escolares donados por países europeos con temas, cuentos y ejemplos de niños europeos, de tal forma que no tiene incentivo para aprender. Estos ejemplos reales, tomados de Amartya Sen, ponen el acento en lo que el autor indio denomina, parafraseando a Marx, "fetichismo» de los bienes, pues no siempre se transforman en opciones reales para realizar un plan de vida autónomo. A la pregunta «qué se debe distribuir» (¿igualdad de qué?) Sen responde con lo que denomina "capacidades» (capabilities), es decir, lo que la gente puede hacer o ser con los bienes que recibe, desde lo más básico - ser capaz de moverse- hasta lo más complejo, como poder estudiar o poder participar en la vida social de la comunidad (Sen, 2012). Lo que se debe igualar, por lo tanto, no son bienes primarios, recursos o ingresos, sino la libertad para lograr nuestros fines con esos bienes, o lo que es lo mismo, la capacidad para elegir entre diferentes formas de funcionar bien (functionings). 
3.2 ¿Cómo se distribuye? El criterio maximín, el utilitarismo de John Harsanyi y las intuiciones de la gente

Como no podía ser de otra manera, el principio de diferencia recibió también críticas tempranas. La principal, la de John Harsany, supone además una reivindicación del utilitarismo, al que Rawls había atacado radicalmente. El principio de diferencia rawlsiano se basa en el criterio maximín de decisión en contextos de incertidumbre (criterio que recomienda elegir aquella opción que nos ofrecería al menos el máximo de los mínimos), por eso el principio dicta que la distribución sea la máxima posible para los que tienen menos. Como tras el velo no sabemos lo que nos deparará la suerte, Ralws considera que el maximín es el criterio de distribución más racional. Pero esto supone que las personas tienen una gran aversión al riesgo, ya que deciden como si temieran que les puede pasar lo peor y deben evitarlo. John Harsanyi, que considera que este criterio de distribución es muy conservador y poco acorde con la psicología de la gente, propone la siguiente alternativa:

La persona en cuestión elegiría [en la posición original] entre... dos sistemas sociales alternativos suponiendo que bajo cualquiera de los sistemas tendría la misma probabilidad, $1 / n$, de estar en el lugar de la persona que está mejor, o en el de la segunda persona que está mejor, o en de la tercera persona que está mejor, etc., así hasta llegar a la persona más desfavorecida. A esto lo voy a llamar el supuesto de la equiprobabilidad (Harsanyi, 1975, p. 598).

Si creemos que este supuesto es más realista por ser menos temeroso con respecto al riesgo (sin ser por ello arriesgado), tendremos que admitir, según Harsanyi, que el decisor racional ya no adoptará el criterio maximín, sino el de maximización de la utilidad esperada, dada la probabilidad (igual para todos) de que nos «toque» estar mejor o peor en la sociedad. Partiendo de estos dos principios equiprobabilidad y maximización de la utilidad esperada- el individuo elegirá siempre una sociedad que proporcione a las personas la mayor utilidad promedio (principle of average utility). En otras palabras, la mejor sociedad en términos de justicia distributiva no sería rawlsiana, sino utilitarista ${ }^{5}$.

Con todo, un ingente número de trabajos experimentales parece que le quitan la razón tanto a Rawls como a Harsanyi sobre lo que elegirían individuos racionales. Tras el velo experimental de ignorancia los sujetos reales eligen un «paquete» de principios de justicia en el cual se atribuye al mérito, la igualdad, la eficiencia y las necesidades mayor o menor peso dependiendo de la actitud individual frente al riesgo, que no tiene por qué ser de aversión, como en Rawls, ni neutral como en Harsanyi (Michelbach et al., 2003). Por otra parte, llama la atención que mucha más gente elija el principio de diferencia rawlsiano cuando debate sin velo de ignorancia sobre distintos principios, que cuando decide tras un velo de ignorancia (Herne y Suojanen, 2004).

Puede que parezca que estos experimentos están muy lejos de las teorías normativas de la justicia. Pero si consideramos que para Rawls los principios de justicia surgen de un equilibrio reflexivo entre las intuiciones de la gente, el análisis de diversos principios de justicia y un conocimiento solvente sobre el funcionamiento de la sociedad, se aceptará entonces que la filosofía experimental pueda cuestionar -y lo está haciendo- ese supuesto equilibrio, lo que resulta más que útil para el debate normativo (Hassoun, 2016).

\footnotetext{
${ }^{5}$ Para reducir la carga de esta crítica Rawls señala que «no es esencial que las partes usen la regla maximín en la posición original. No es más que una útil herramienta heurística» (Rawls, 2002, p. 141).
} 


\section{Justicia, mercado y derechos: Robert Nozick}

A diferencia de Rawls, y en parte como respuesta a su obra, el objetivo central de Robert Nozick en Anarquía, Estado y utopía (1988) es la defensa del mercado libre como el mecanismo social más justo de distribución de bienes. Dicho esto, ¿cómo relaciona Nozick mercado y justicia teniendo en cuenta que el mercado genera desigualdades considerables? La teoría de la justicia de Nozick afirma, de manera muy resumida, lo siguiente: si asumimos que todo el mundo tiene derecho a los bienes que posee si los obtiene de manera legítima, entonces una distribución justa de bienes sólo puede ser aquella que resulte del libre intercambio de esos bienes. Por ello ningún gobierno puede realizar políticas redistributivas legítimamente sin cometer una injusticia, a saber, aquella que consiste en quitarle a alguien lo que es suyo (vía impuestos, por ejemplo) para dárselo a otros. Si el uno por ciento más rico de la población ha obtenido esa riqueza de forma legítima la desigualdad resultante no será injusta. ¿Qué principios avalan esta afirmación?

La teoría de Nozick se apoya en tres principios centrales:

a) Principio de transferencia: lo que es adquirido con justicia puede ser transferido libremente.

b) Principio de adquisición inicial justa: principio que determina cómo se puede adquirir la propiedad inicial de las cosas.

c) Principio de rectificación de injusticias: permite tratar los casos en los que la adquisición o transferencia de bienes no fue justa.

A partir de estos principios Nozick llega a la conclusión de que sólo es legítimo un Estado mínimo que se limite a proteger a las personas contra el abuso, el fraude, el robo, etc. Cualquier política redistributiva (financiación pública de colegios, carreteras, hospitales, parques) significará coaccionar a la gente contra su voluntad.

¿Cómo se justifica esta teoría, de dónde proceden sus principios? Nozick se vale de dos argumentos de distinta naturaleza para defender su propuesta: el experimento mental sobre el mítico jugador de baloncesto de la NBA, Wilt Chamberlain, quien gana millones de dólares de forma legítima porque la gente paga por verlo jugar, y el de la autopropiedad. Nos centraremos solo en el más sólido, el de la autopropiedad ${ }^{6}$.

En Anarquía, Estado y Utopía se desarrolla una teoría de la justicia distributiva partiendo de un principio moral aceptado por todos (a saber, que no somos esclavos y que, por lo tanto, cada cual es dueño de sí mismo), estableciendo luego una regla de justicia (la de la justa apropiación inicial de los recursos externos) y deduciendo el tipo de distribución de bienes (no igualitaria) que sería justa. Su argumentación se puede resumir como sigue (me ciño a la inmejorable exposición de Gerald Cohen):

1. Nadie es esclavo de nadie en medida alguna, por ello

2. Nadie pertenece, totalmente o en parte, a nadie, por ello

3. Toda persona se pertenece a sí misma. Por lo tanto

4. Toda persona tiene que ser libre de hacer lo que le plazca si no perjudica a nadie, y no se le puede exigir que ayude a nadie (1995, pp. 113-115).

\footnotetext{
${ }^{6}$ Si Wilt Chamberlain firma un contrato por el cual se quedará con el 10 por ciento del precio de las entradas cuando su equipo juegue en casa y, de esa forma, al final de la temporada Wilt gana un millón de dólares (de los años 60), el incremento de riqueza será justo según Nozick. Dado que la gente paga por ver a Wilt de forma voluntaria la desigualdad resultante no será injusta. En un trabajo experimental del economista James Konow (2003, p. 1207) se muestra que un 41 por ciento de los participantes en el estudio (137) está de acuerdo en que ese resultado es justo, mientras que un 59 lo considera injusto.
} 
Puesto que soy dueño de mí mismo, nadie puede exigirme nada sin mi consentimiento. De otra forma se me estaría coaccionando y no sería dueño de mí (sería un esclavo). Si el Estado me quita, en contra de mi voluntad, dinero o bienes que me pertenecen legítimamente para ayudar a los más desfavorecidos, éstos recibirán la ayuda porque el Estado me ha coaccionado, lo cual supone que soy, en parte, un esclavo.

Ahora bien, hasta ahora no se ha dicho nada de la legitimidad de mis posesiones, de «lo que es mío» (esto es, de la propiedad privada): los cuatro primeros argumentos no bastan para defender ni el derecho a la posesión privada de recursos ni las situaciones no igualitarias generadas por el mercado. Para ello Nozick introduce la siguiente premisa de carácter histórico:

5. Los recursos externos, en su estado original, no pertenecían a nadie (Cohen, 1995, pp. 113-115).

A partir de 4 y de 5, Nozick deduce su principio de justa adquisición:

6. Condición lockeana: toda persona puede acumular para sí cantidades ilimitadas de recursos naturales sin con ello no perjudica a nadie (no empeora su situación). De donde se deduce que

7. Cantidades desiguales de recursos naturales pueden ser legítimamente propiedad privada de una parte de la población.

8. Una amplia desigualdad de resultados es inevitable, o sólo se puede evitar a costa de violar los derechos de las personas sobre sí mismas y sobre las cosas (Cohen, 1995, pp. 113-115).

Así pues, si todo el mundo es dueño de sí mismo y los recursos naturales pueden ser legítimamente acumulados por unos pocos, siempre que los demás no vean empeorada su situación: el resultado será una sociedad en la que resulten legítimas enormes desigualdades que un Estado no debe corregir. De aquí la apuesta anarcocapitalista de Nozick, que trata de proporcionar fundamentos normativos al principio de la justa adquisición de títulos de propiedad privada (entitlement theory), apoyándose en el principio moral de la autopropiedad y en el principio histórico de que en su origen los recursos externos no pertenecían a nadie.

No se debe pasar por alto que según condición lockeana las apropiaciones son justas sólo si no perjudican a nadie. ¿Se puede asegurar, entonces, que las sociedades se han desarrollado exclusivamente sobre la base de adquisiciones originales que no perjudicaron a nadie? Si no se puede afirmar -y hay razones históricas para pensar que no se puede- el principio nozickiano de rectificación de injusticias supondría la puesta en práctica de políticas redistributivas más radicales aún que las que se desprenden de la teoría de Rawls, echando por tierra parcialmente la defensa del Estado mínimo y del mercado libre.

5. ¿Entre quiénes se distribuye? Comunitarismo, cosmopolitismo y fronteras de la justicia

Para todas las teorías de la justicia distributiva que acabamos de presentar la respuesta a las preguntas «qué se distribuye» y "cómo se distribuye» es muy distinta (especialmente en el caso de Nozick). Sin embargo, la respuesta a la pregunta «entre quiénes se distribuye» es similar. En efecto, el sujeto de la justicia es siempre más o menos el mismo: ciudadanos racionales que, para asegurar la imparcialidad, se sitúan por encima de toda determinación social y personal al elegir los principios de justicia: 
Según la visión liberal del yo, se considera que los individuos son libres de cuestionar su participación en las prácticas sociales existentes, y de hacer elecciones independientemente de éstas, en el caso de que tales prácticas ya no merezcan ser seguidas. Como resultado, los individuos ya no se definen en cuanto participantes de ninguna relación económica, religiosa, sexual o recreativa en particular, ya que son libres de cuestionar y rechazar cualquier relación. Rawls resume esta versión liberal afirmando que "el yo es previo a sus fines" (Kymlicka, 1995, p. 229).

Cuando tratamos de dar respuesta a la cuestión sobre los sujetos de la justicia, cuando nos preguntamos entre quiénes se distribuyen los recursos, no podemos apelar, según la tradición comunitarista, a un yo desvinculado, no comprometido (unencumbered self), capaz de elegir neutral e imparcialmente principios ideales y universales de justicia. Para los comunitaristas la concepción liberal del yo resulta vacía, pues atenta contra la forma en que nos percibimos, esto es, como individuos que se hallan inmersos en las más diversas prácticas comunitarias (tradiciones, culturas, lenguajes, etc., diversos). El yo no es previo a sus fines, sino que se constituye en función se fines que están delimitados por la comunidad a la que se pertenece y de la que resulta muy difícil desvincularse. En ese sentido, la crítica feminista a Rawls es muy ajustada: sin reconocer las relaciones de dominación en el seno de la familia -partiendo de un ciudadano racional y razonable como sujeto moral- es imposible que muchas mujeres y niñas tengan acceso a bienes sociales primarios o los puedan disfrutar de hecho (Okin, 1989).

\subsection{Michael Walzer y las esferas de la justicia}

En su influyente obra Las esferas de la justicia (1993) Walzer propone lo que denomina una teoría pluralista de la justicia dirigida a la elaboración de un concepto «complejo» de igualdad. Walzer rechaza la noción «simple» de la igualdad liberal que trata de hallar un criterio de justicia único que iguale a todo el mundo en todos los ámbitos posibles. Partiendo del hecho de que los personas estamos íntimamente ligadas a una comunidad que nos proporciona una identidad y una forma de entender en común las prácticas sociales, Walzer considera que no se pueden distribuir los distintos bienes de interés social mediante un único criterio de distribución (Gargarella, 1999, p. 135). Las convenciones sociales de nuestras comunidades atribuyen esferas distintas a los diversos bienes que hay que distribuir, y en cada esfera rige un criterio distributivo distinto. Así, por ejemplo, en nuestra sociedad los bienes que se precisan para tener una buena salud se distribuyen según el principio «a cada cual según sus necesidades»; los premios y castigos se distribuyen según el mérito; la educación superior según el talento; la ciudadanía según las tradiciones de la comunidad y la riqueza según la habilidad y la suerte que se tenga en el mercado. Y lo que es más, distintas comunidades valoran bienes distintos y desarrollan también principios distributivos diferentes.

La teoría de Walzer se asienta, pues, en dos ideas básicas. En primer lugar, cada tipo de recurso debe distribuirse según un principio adecuado a la esfera que le corresponde (salud, educación, política, riqueza). En segundo lugar, el éxito en una esfera no debe implicar el dominio sobre otras. El éxito de una persona en el mercado no debe implicar que esa persona pueda comprar votos, por ejemplo.

El esfuerzo de Walzer para extraer los principios de justicia de las prácticas sociales de la comunidad en distintas esferas está encaminado, por una parte, a cuestionar que la filosofía política deba ser una labor abstracta, ajena a la sociedad, cuyo fin consista en hallar los verdaderos y únicos principios de justicia y, por otra, supone una crítica a la noción rawlsiana de los bienes primarios como bienes que desea cualquier individuo racional en toda sociedad. 
Sin embargo, como se ha señalado con frecuencia, dicho esfuerzo encierra dos de los puntos más débiles no sólo de la obra de Walzer, sino de todo el pensamiento comunitarista: el relativismo en temas de justicia y la concepción idealizada de la comunidad. Walzer afirma que la sociedad es justa cuando es fiel a la forma de vida compartida por sus miembros. Así, por ejemplo, sería injusto que se llevaran a cabo distribuciones igualitarias en una sociedad cuyas tradiciones aceptan el sistema de castas. Lo cual no implica, a su modo de ver, que una sociedad justa no deba establecer mecanismos alternativos de distribución para los que no estén de acuerdo con las tradiciones. Pero esto resulta difícil de entender, pues si la justicia tiene que ver con las prácticas sociales compartidas, con la compresión común de los miembros de una comunidad, ¿cómo pueden ponerse de acuerdo, hablar siquiera sobre temas de justicia quienes, por pertenecer a comunidades distintas 0 , incluso perteneciendo a una misma comunidad, no comparten las mismas prácticas y tradiciones?

\subsection{Justicia distributiva cosmopolita}

Alguno de las cuestiones planteadas por la concepción de la justicia de Walzer, así como los problemas que entraña, apuntan a uno de los grandes problemas actuales: la tensión entre lo local y lo global, tensión a la que no son ajenos los problemas de justicia distributiva. A la hora de tratar con esos problemas nos enfrentamos necesariamente a la pregunta sobre el ámbito en el que hemos de resolverlos. Así, la pregunta "entre quiénes se distribuye» se vuelve dolorosamente cruel, pues supone incluir a unos seres humanos en la distribución y dejar a otros fuera incluso aunque les cueste la vida. Distribuir entre los nuestros, entre los de nuestro país, entre los de nuestra tierra o comunidad puede ser justo, pero hace que las fronteras establezcan límites muy severos a los principios de justicia (Velasco, en prensa). ¿Cómo hacer frente a este complejo problema?

Hemos visto ya que para Rawls, por ejemplo, hay que distribuir siempre para favorecer a los más desventajados, a los que están peor. ¿Pero peor dónde? Esto se ha discutido acaloradamente, porque para muchos autores el principio de diferencia es aplicable a la comunidad mundial (Pogge, 2005). Sin embargo, para Rawls no es así: su teoría de la justicia está pensada para sociedades que cumplen unos requisitos institucionales mínimos (deben ser democracias, entre otras cosas). Más allá de las fronteras de aquellas naciones que cumplen con esos requisitos democráticos mínimos se impone el deber de ayudar (Rawls, 2002), pero no se puede imponer a terceros teoría de la justicia alguna: «No se pueden exigir que todos los pueblos sean liberales» (Rawls, 1996, p. 42) ${ }^{7}$.

Chocan aquí una idea local de comunidad («liberal» en este caso) y la idea de una comunidad de seres humanos, idea que se halla en la base del cosmopolitismo:

A grandes rasgos, la idea [del cosmopolitismo] es que debemos apreciar que somos miembros de una comunidad global de seres humanos. Como tales, tenemos responsabilidades con otros miembros de la comunidad global. Tal y como Martha Nussbaum lo elabora, debemos lealtad "a la comunidad mundial de seres humanos" y esta afiliación debe constituir una lealtad primaria. (Brock 2009, p. 9).

Una teoría cosmopolita de la justicia tendría que acompasar, al menos de momento, ese ideal con la existencia de Estados-nación y, por lo tanto, de intereses nacionales. Ahora bien, ¿nos aleja este problema de la aproximación normativa a la justicia para entrar en el terreno real de la política y la negociación entre naciones?

\footnotetext{
7 «Liberales» en el sentido estadounidense, no europeo del término.
} 
No necesariamente. Partiendo de la teoría de las capacidades humanas y de elementos de la teoría de Rawls, Martha Nussbaum ha propuesto diez principios (pero podrían ser más) para la gestión de la estructura global. Citamos a continuación los que se relacionan más directamente con la justicia distributiva:

- «Sobredeterminación de la responsabilidad: el ámbito nacional interno no puede nunca rehuirla ${ }^{8}$. (...)

- Las naciones más prósperas tienen la responsabilidad de dar una porción de su PIB a otras naciones más pobres. (...)

- Las grandes empresas multinacionales tienen responsabilidades a la hora de promover las capacidades humanas en las regiones en las que operan. (...)

- Las principales estructuras del orden económico mundial deben estar diseñadas de tal modo que sean justas con los países pobres y en vías de desarrollo. (...)

- Todas las instituciones (y la mayoría de) los individuos deberían prestar especial atención a los problemas de los desfavorecidos en cada nación y en cada región» (Nussbaum, 2007, pp. 311-316).

Las preguntas sobré cómo se distribuye, qué se distribuye y entre quiénes nos han llevado hasta este punto en el que el ámbito de aplicación de la justica es el mundo entero, recuperando el viejo ideal cosmopolita. Propuestas como la de Nussbaum, razonables pero difíciles de llevar a la práctica, deberían ser el horizonte de toda teoría normativa de la justicia.

\section{Bibliografía}

Bobbio, N. (1993). Igualdad y libertad. Barcelona: Paidós.

Brock, G. (2009). Global Justice. A Cosmopolitan Account, Oxford: Oxford University Press.

Cohen, G. (1995). Self-ownership, Freedom and Equality. Cambridge: Cambridge University Press.

Dworkin, R. (2003). Virtud soberana. Barcelona: Paidós.

Gargarella, R. (1999), Las teorías de la justicia después de Rawls. Barcelona: Paidós.

Harsanyi, J. (1975). Can the maximin principle serve as a basis for morality? A critique of John Rawls's theory. American Political Science Review, 69, 594-606.

Hassoun, N. (2016). Experimental or empirical political philosophy. En J. Sytsma y W. Buckwalter (eds.), A Companion to Experimental Philosophy (pp. 234-246). Oxford: Blackwell.

Herne, K. y Suojanen, M. (2004). The role of information in choices over income distribution. Journal of Conflict Resolution, 48, pp. 173-193.

Konow, J. (2003). Which is the fairest one of all? A Positive Analysis of Justice Theories. Journal of Economic Literature, 41 (4), pp. 1188-1239.

Kymlicka, W. (1995). Filosofía política contemporánea, Barcelona: Ariel.

Lamont, J. y Favor, Ch. (2017). Distributive Justice. En Edward N. Zalta (ed.), The Stanford Encyclopedia of Philosophy. Recuperado de: https://plato.stanford.edu/archives/win2017/entries/justice-distributive/

Michelbach, P., Scott, J., Matland, R. y Bornstein, B. (2003). Doing Rawls justice: an experimental study of income distribution norms. American Journal of Political Science, 47, pp. 523-539.

\footnotetext{
${ }^{8}$ En otras palabras, las naciones más ricas deben hacer todo lo posible para que las pobres alcancen un «umbral mínimo de capacidad».
} 
Milanovic, B. (2018). Desigualdad mundial. Un nuevo enfoque para la era de la globalización. México: Fondo de Cultura Económica.

Nozick, R. ([1974] 1988). Anarquía, estado y utopía. México: Fondo de Cultura Económica.

Nussbaum, M. (2007). Las fronteras de la justicia. Consideraciones sobre la exclusión. Barcelona: Paidós.

Okin, S. (1989). Justice, Gender and the Family. Nueva York: Basic Books.

Pogge, Th. (2005). La pobreza en el mundo y los derechos humanos. Barcelona: Paidós.

Rawls, J. (1971). A Theory of Justice. Cambridge, Mass.: Harvard University Press [traducido al español en Rawls, J. (1978). Teoría de la justicia. México: Fondo de Cultura Económica].

Rawls, J. (1996). El liberalismo político. Barcelona: Crítica.

Rawls, J. (1999). A Theory of Justice. Revised Edition. Cambridge, Mass.: Harvard University Press.

Rawls, J. (2002). La justicia como equidad. Una reformulación. Barcelona, Paidós [versión original Rawls, J., Justice as Fairness. A Restatement, Cambridge, Mass.: Harvard University Press].

Scanlon, T. M. (1986). Equality of resources and equality of welfare: A forced marriage?. Ethics, 97(1), 111-118.

Sen, A. (2012). La idea de la justicia, Madrid: Taurus.

van Parijs, Ph. (1995). Real Freedom for All. Oxford: Clarendon Press [traducido al español en van Parijs, Ph. (1996). Libertad real para todos. Barcelona: Paidós].

Walzer, M. ([1983] 1993), Las esferas de la justicia. México: Fondo de Cultura Económica.

Velasco, J. C. (en prensa). Hacia una visión cosmopolita de las fronteras. Desigualdades y migraciones desde la perspectiva de la justicia global. Revista Internacional de Sociología.

Venezia, L. (2007). Bienes sociales primarios versus utilidad. Análisis Filosófico, XXVII(2), 185-219. 